\title{
Analisis Faktor-Faktor yang Mempengaruhi Pemberian Pinjaman Pada KSU Kencana Makmur Sugihan lamongan
}

\author{
Nurus safa'atillah \\ Universitas Islam Lamongan \\ nurussafaatillah@gmail.com
}

\begin{abstract}
Abstrak Di era ini, persaingan yang begitu ketat membuat koperasi - koperasi harus mampu memainkan strategi yang handal dan mampu mempertahankan pemberian pinjaman. Dalam penelitian ini penulis mengambil variabel bebas antara lain character, capacity, capital, collateral dan condition of economi untuk digunakan sebagai acuan pemberian pinjaman. Penelitian ini bertujuan untuk mengetahui apakah character, capacity, capital, collateral dan condition of economi berpengaruhi secara parsial maupun simultan terhadap pemberian pinjaman pada KSU Kencana Makmur Sugihan. Metode analisi yang digunakan adalah metode kuantitatif dengan menggunakan uji validitas, uji reliabilitas, uji regresi linier berganda, koefisien determinasi, uji F, uji t, dengan menggunakan olah data SPSS versi 20. Hasil analisis uji validitas dan uji reliabilitas menunjukan hasil tiap variabel dinyatakan valid dan reliabel. Dari hasil uji regresi linier berganda didapatkan suatu persamaan regresi sebagai berikut : $\mathrm{Y}=0,419+0,604 \mathrm{X}_{1}+0,041 \mathrm{X}_{2}+$ $0,734 X_{3}+0,311 X_{4}+0,295 X_{5}$. Untuk hasil uji $t$ diperoleh $t_{\text {hitung }}(X 1)=$ $2,355>\mathrm{t}_{\text {tabel }}=1,99495$ yang berarti bahwa character mempunyai pengaruh yang signifikan secara parsial terhadap pemberian pinjaman, sedangkan $t_{\text {hitung }}(\mathrm{X} 2)=0,255<\mathrm{t}_{\text {tabel }}=1,99495$ yang berarti bahwa capacity tidak mempunyai pengaruh yang signifikan secara parsial terhadap pemberian pinjaman. sedangkan $t_{\text {hitung }}$ $(\mathrm{X} 3)=4,380>\mathrm{t}_{\text {tabel }}=1,99495$ yang berarti bahwa capital mempunyai pengaruh yang signifikan secara parsial terhadapa pemberian pinjaman. sedangkan thitung $(\mathrm{X} 4)=1,753>\mathrm{t}_{\text {tabel }}=1,99495$ yang berarti bahwa collateral tidak mempunyai pengaruh yang signifikan secara parsial terhadap pemberian pinjaman. sedangkan thitung $(\mathrm{X} 5)=1,397>\mathrm{t}_{\text {tabel }}=1,99495$ yang berarti bahwa condition of economil tidak mempunyai pengaruh yang signifikan secara parsial terhadap pemberian pinjaman. Hasil untuk uji $\mathrm{F}$ diperoleh nilai $\mathrm{F}_{\text {hitung }}$ 9,170 > $\mathrm{F}_{\text {tabel }} 2,35$ yang berarti variabel $\mathrm{X} 1, \mathrm{X} 2, \mathrm{X} 3, \mathrm{X} 4$ dan $\mathrm{X} 5$ berpengaruh secara simultan terhadap pemberian pinjaman. Dengan demikian adanya penelitian ini, diharapkan dapat dijadikan sebagai bahan pertimbangan untuk meningkatkan pemberian pinjaman.
\end{abstract}

Kata Kunci character, capacity, capital, collateral, condition of economi, pemberian pinjaman. 


\section{PENDAHULUAN}

Lembaga keuangan memiliki peranan yang sangat penting dalam menunjang kesejahteraan masyarakat di suatu negara. Di Indonesia mayoritas warga negaranya bergantung pada lembaga keuangan untuk mendapatkan bantuan pendanaan dan tempat untuk menyimpan uang. Munculnya berbagai lembaga keuangan bank dan bukan bank memang banyak menguntungkan bagi masyarakat, terutama dalam bidang finansial untuk memenuhi berbagai kebutuhan hidup. Baik bank negeri maupun swasta banyak bersaing dengan lembaga keuangan bukan bank seperti koperasi simpan pinjam.

Koperasi simpan pinjam didirikan bertujuan untuk memberi kesempatan kepada anggotanya untuk memperoleh pinjaman dengan persyaratan mudah dan bunga yang relatif ringan. Koperasi simpan pinjam juga berusaha untuk mencegah para anggotanya agar tidak terlibat dalam hutang rentenir, dengan jalan meningkatkan tabungan dan mengatur pemberian pinjaman uang dengan bunga yang serendah-rendahnya, koperasi simpan pinjam menghimpun dana dari para anggotanya yang kemudian menyalurkan kembali dana tersebut kepada para anggotanya. Sebagai lembaga keuangan bukan bank yang berfungsi menghimpun dan menyalurkan dana dalam bentuk pinjaman atau kredit, koperasi simpan pinjam berusaha memberikan kemudahan dalam layanan pemberian kredit. Namun pada umumnya masyarakat masih kurang memahami tata cara dan syarat pemberian kredit.

Kata kredit berasal dari bahasa latin credere yang artinya kepercayaan. Maksud dari percaya, bagi pemberi kredit adalah percaya kepada penerima kredit bahwa kredit yang disalurkan pasti akan dikembalikan sesuai dengan perjanjian. Sedangkan bagi penerima kredit mempunyai kewajiban membayar sesuai jangka waktu yang telah disepakati. Dalam masyarakat, pengertian kredit sering disamakan dengan pinjaman, artinya bila seseorang mendapat kredit berarti mendapat pinjaman. Untuk meyakinkan calon nasabah benar-benar dapat dipercaya maka harus menganalisa kredit terlebih dahulu, yang mencakup latar belakang nasabah, prospek usahanya, jaminan yang diberikan serta faktor-faktor pendukung lainnya. Tujuan analisa ini yaitu untuk meyakinkan bahwa kredit yang diberikan benar-benar aman, sehingga bisa memperlancar proses pemberian kredit, dan mencegah terjadinya kredit macet. Kriteria yang harus diperhatikan yaitu mencakup 5C yang meliputi Character, Capacity, Capital, Collateral, dan Condition. Penilaian prinsip 5c ini sangat penting untuk diterapkan oleh koperasi sebagai suatu kegiatan pemeriksaan, penelitian, dan analisa terhadap kelengkapan, keabsahan, dan kelayakan berkas/surat/data permohonan kredit calon debitur hingga dikeluarkannya suatu keputusan apakah kredit tersebut diterima atau ditolak. Berdasarkan uraian yang telah diuraikan diatas, penulis tertarik untuk melakukan penelitian dengan judul "ANALISIS FAKTOR-FAKTOR YANG MEMPENGARUHI PEMBERIAN PINJAMAN PADA KSU KENCANA MAKMUR SUGIHAN".

Rumusan masalah pada penelitian ini adalah

1. Apakah character, capacity, capital, collateral, dan condition of economi berpengaruh parsial terhadap pemberian pinjaman pada KSU Kencana Makmur Sugihan? 
2. Apakah character, capacity, capital, collateral, dan condition of economi berpengaruh simultan terhadap pemberian pinjaman pada KSU Kencana Makmur Sugihan?

3. Diantara variabel character, capacity, capital, collateral, dan condition of economi manakah yang paling dominan berpengaruh terhadap pemberian pinjaman pada KSU Kencana Makmur Sugihan?

\section{LANDASAN TEORI}

Koperasi berasal dari bahasa latin yaitu coopere atau dalam bahasa Inggris disebut cooperation. Co berarti bersama dan operation berarti bekerja atau berusaha (to operate). koperasi merupakan badan usaha yang terdiri dari kumpulan orang-orang yang bertujuan untuk mensejahterakan para anggotanya, walaupun dalam praktiknya koperasi juga melayani kepentingan umum Menurut Kasmir (2012:286).

Menurut Muljono (2012:1) mendefinisikan bahwa koperasi adalah badan usaha yang beranggotaan orang-seorang / badan hukum. Pada umumnya kriteria yang digunakan dalam menentukan pinjaman baik dalam koperasi maupun perusahaan lainnya adalah sama. Sebelum suatu fasilitas kredit diberikan, koperasi harus yakin bahwa kredit yang diberikan benar-benar akan kembali. Keyakinan tersebut diperoleh dari hasil penilaian kredit sebelum kredit tersebut disalurkan. Penilaian kredit oleh koperasi dapat dilakukan dengan cara untuk mendapatkan keyakinan tentang nasabahnya yang benar-benar menguntungkan dilakukan dengan analisis $5 \mathrm{c}$.

Adapun analisis dengan 5c antara lain :

1. Character merupakan suatu keyakinan bahwa sifat atau watak dari orang-orang yang akan diberikan kredit benar-benar dapat dipercaya. Indicator dari character :

a) watak,gaya hidup debitur dalam mengajukan kredit dilihat dari kooperatifan debitur.

b) komitmen mengembalikan kredit debitur untuk kooperatif, jujur, dan tanggung jawab dalam membayar kredit yang telah tertuang dalam akad kredit.

2. Capacity digunakan untuk melihat kemampuan nasabah yang mengajukan kredit dalam bidang bisnis yang dihubungkan dengan kemampuannya untuk menjalankan usaha. Indicator dari capacity :

a) kemampuan memperoleh pendapatan atau laba dari hasil menjalankan kegiatan usahanya yang digunakan untuk membayar kredit setiap bulannya.

b) kemampuan debitur mengelola usahanya agar berkembang dari waktu ke waktu untuk dapat melunasi kreditnya.

3. Capital ini digunakan untuk melihat penggunaan modal yang dipunyai nasabah apakah efektif atau tidak. Keefektifan penggunaannya dapat dilihat melalui laporan keuangan (neraca dan laporan laba rugi). Indicator dari capital :

a) sumber modal yang dimiliki debitur untuk membiayai usahanya dan di dapat dari mana untuk membayar kredit,

b) jenis modal yang dimiliki debitur dapat berupa kas ataupun non kas.

4. Collateral yaitu barang yang dijaminkan hendaknya melebihi jumlah kredit yang diberikan. Jaminan juga harus diteliti keabsahannya sehingga jika terjadi suatu masalah, maka jaminan yang dititipkan dapat dipergunakan mungkin. Adapun indicator dari collateral : 
a) nilai jual barang yang digunakan sebanding atau melebihi plafond kredit yang diajukan

b) kepemilikan barang jaminan yang diberikan debitur kepada bank memiliki keaslian dokumen yang sah sebagai keamanan bagi bank.

5. Condition of economy didenifisikan sebagai penilaian suatu kondisi ekonomi debitur yang dapat mempengaruhi kegiatan usaha debitur dimasa sekarang dan masa depan yang berdampak pada lancer atau tidaknya debitur daam membayar kredit. Indicator dari condition of economy :

a) kondisi ekonomi terkait kondisi social,politik budaya, ekonomi perusahaan dalam kelancaran pembayaran kredit bila diberikan pinjaman

b) kondisi ruang lingkup pemasaran dalam persaingan pasar yang kompleks.

Menurut Alifah Karamina (2012) keputusa kredit adalah persetujuan secara tertulis dari analis kredit yang berwewenang, terhadap besarnya kredit yang telah disususun jenis dan nilai angunan kredit.

Indicator pemberian pinjaman dapat dilihat dari :

a) pencarian informasi mengenai debitur dengan melihat berbagai aspek pengevaluasian syarat pengajuan kredit kepada debitur yang mengajukan kredit

b) pertimbangan keamanan kredit

c) persepsi melihat kinerja atau performance perusahaan debitur apakah memiliki potensi yang baik dan menjanjikan untuk kedepanya.

\section{METODOLOGI PENELITIAN}

Jenis penelitian yang digunakan dalam penelitian ini yaitu penelitian kuantitatif. Menurut Sugiyono (2010) Metode kuantitatif merupakan suatu metode penelitian yang bersifat induktif, objektif dan ilmiyah dimana data yang diperoleh berupa angka-angka (score, nilai) atau pertanyaan-pertanyaan yang di nilai, dan dianalisis dengan analisis statistik.

Menurut Sugiyono (2010:80). Populasi adalah wilayah generasi yang terdiri atas obyek/subyek yang mmpunyai kualitas dan karakteristik tertentu yang ditetapakan oleh penelitian untuk dipelajari dan kemudian ditarik kesimpulannya. . Populasi dalam penelitian ini adalah 300 pemberian pinjaman pada nasabah KSU Kencana Makmur Sugihan dan diperoleh sampel sebanyak 75 responden dengan menggunakan Purphosive Sampling (sampling pertimbangan). Dimana Teknik Purphosive Sampling adalah pengambilan sampel yang digunakan berdasarkan pertimbangan perorangan atau pertimbangan peneliti (Sugiyono, 2015). Adapun jenis data yang digunakan yaitu :

\section{a. Data Primer}

Merupakan sumber data penelitian yang diperoleh secara langsung dari sumber asli (tidak melalui media perantara). Data primer secara khusus dikumpulkan oleh peneliti untuk menjawab pertanyaan penelitian. Penelitian melakukan wawancara langsung yang berupa pertanyaan mengenai faktor-faktor yang mempengaruhi pinjaman.

b. Data skunder

Merupakan sumber data penelitian yang diperoleh peneliti secara tidak langsung melalui media perantara (diperoleh dan dicatat oleh pihak lain). Data sekunder yang digunakan dalam penelitian ini adalah berupa data internal perusahaan, yaitu profil perusahaan, latar 
belakang perusahaan, visi dan misi perusahaan, struktur organisasi perusahaan, serta produk dan jasa perusahaan.

Dalam penelitian ini menggunakan pernyataan yang nantinya akan dianalisa secara kuantitatif dengan menggunakan Skala Likert. Skala Likert adalah skala yang digunakan untuk mengukur sikap, pendapat, dan persepsi seseorang atau sekelompok orang tentang fenomena sosial (Sugiyono, 2015).

Variabel - variabel yang digunakan dalam penelitian ini ada dua, yaitu variabel bebas (independent) dan variabel terikat (dependent).

1. Variabel Bebas ( Independen Variabel $=X$ )

Yaitu variabel yang dalam hubungannya dengan variabel lain bertindak sebagai penyebab yang mempengaruhi variabel lain. (Sugiyono, 2016:59). Adapun variabel bebas yang digunakan dalam penelitian ini adalah:

a. Character $\left(\mathrm{X}_{1}\right)$

Menurut (Sugiono : 2011 :39) Character merupakan suatu keyakinan bahwa sifat atau watak dari orang-orang yang akan diberikan kredit benar-benar dapat dipercaya Penilaian. Indicator dari character :

1) Watak

2) Jujur, bertanggung jawab

\section{b. Capacity $\left(\mathrm{X}_{2}\right)$}

Menurut ( Sugiono: 2011 :39 ) capacity digunakan untuk melihat kemampuan nasabah yang mengajukan kredit dalam bidang bisnis yang dihubungkan dengan kemampuannya untuk menjalankan usaha. Indicator dari capacity :

1) Kemampuan memperoleh pendapatan atau laba

2) kemampuan debitur mengelola usaha

c. capital $\left(\mathrm{X}_{3}\right)$

Menurut ( Sugiono: 2011 :39 ) Capital ini digunakan untuk melihat penggunaan modal yang dipunyai nasabah apakah efektif atau tidak. Keefektifan penggunaannya dapat dilihat melalui laporan keuangan (neraca dan laporan laba rugi). Indicator dari icapital :

1) sumber modal

2) jenis modal

d. Collateral $\left(\mathrm{X}_{4}\right)$

Menurut (Sugiono : 2011 :39) Collateral yaitu barang yang dijaminkan hendaknya melebihi jumlah kredit yang diberikan. Jaminan juga harus diteliti keabsahannya sehingga jika terjadi suatu masalah, maka jaminan yang dititipkan dapat dipergunakan. Indicator dari collateral :

1) nilai jual barang

2) kepemilikan barang jaminan

e. condition of economi $\left(\mathrm{X}_{5}\right)$

Menurut (Sugiono : 2011 :39) Condition of economy didenifisikan sebagai penilaian suatu kondisi ekonomi debitur yang dapat mempengaruhi kegiatan usaha debitur dimasa sekarang dan masa depan yang berdampak pada lancer atau tidaknya debitur daam membayar kredit. Indicator dari condition of economi :

1) kondisi social,politik budaya, ekonomi perusahaan

2) kondisi ruang lingkup pemasaran

2. $\quad$ Variabel Terikat $($ Dependen Variabel $=\mathrm{Y}$ ) 
Yaitu Variabel yang di pengaruhi oleh variabel lain, Sugiyono (2016:59). Dan yang menjadi variabel terikat adalah :

a. Pemberian pinjaman (Y)

Menurut Alifah Karamina (2012) keputusa kredit adalah persetujuan secara tertulis dari analis kredit yang berwewenang, terhadap besarnya kredit yang telah disususun, jenis dan nilai angunan kredit. Indicator dari pemberian pinjaman :

1) pencarian informasi mengenai debitur

2) pertimbangan keamanan kredit

3) persepsi melihat kinerja atau performance perusahaan debitur

\section{HASIL PENELITIAN}

Berdasarkan hasil analisis data yang dilakukan maka dapat disimpulkan sebagai berikut :

2.1 Hasil uji validitas diperoleh nilai $r_{\text {hitung }} X_{1.1}=0,883, X_{1.2}=0,842, r_{\text {hitung }} X_{2.1}=0,902$, $\mathrm{X}_{2.2}=0,893, \mathrm{r}_{\text {hitung }} \mathrm{X}_{3.1}=0,922, \mathrm{X}_{3.2}=0,896, \mathrm{r}_{\text {hitung }} \mathrm{X}_{4.1}=0,908, \mathrm{X}_{4.2}=0,865, \mathrm{r}_{\text {hitung }}$ $\mathrm{X}_{5.1}=0,926, \mathrm{X}_{5.2}=0,916$, dan $\mathrm{Y}_{1}=0,515, \mathrm{Y}_{2}=0,919, \mathrm{Y}_{3}=0,905$. Berdasarkan uji validitas diatas diperoleh $r_{\text {hitung }}>r_{\text {tabel }}$ dimana $r_{\text {tabel }}$ sebesar 0,2272. Sehingga keseluruhan indikator dalam penelitian ini dinyatakan valid.

2.2 Hasil pengujian reliabilitas diperoleh koefisien alpha pada $X_{1}=0,654, X_{2}=0,759$, $\mathrm{X}_{3}=0,786, \mathrm{X}_{4}=0,723, \mathrm{X}_{5}=0,821$ dan $\mathrm{Y}=0,721$ lebih besar dari 0,6 dengan tingkat signifikan $\mathrm{a}=5 \%$ sehingga dapat disimpulkan bahwa instrumen dalam penelitian ini reliabel.

2.3 Hasil regresi berganda dapat ditarik persamaan regresinya yaitu, $Y=0,419+0,604 \mathrm{X}_{1}$ $+0,041 \mathrm{X}_{2}-0,734 \mathrm{X}_{3}+0,311 \mathrm{X}_{4}+0,295 \mathrm{X}_{5}$ yang dapat diartikan sebagai berikut:

$\alpha=0,419$ adalah konstanta yang menunjukkan interpretasi dari nilai Y (pemberian pinjaman) pada saat nilai $\mathrm{X}$ sama dengan nol.

$\mathrm{b}_{1}=0,604$ menunjukkan koefisien regresi untuk $\mathrm{X}_{1}$. Hal ini berarti jika variabel $\mathrm{X}_{1}$ naik satu satuan maka mempengaruhi character pada pemberian pinjaman sebesar $=0,604$. $\mathrm{b}_{2}=0,041$ menunjukkan koefisien regresi untuk $\mathrm{X}_{2}$. Hal ini berarti jika variabel $\mathrm{X}_{2}$ naik satu satuan maka mempengaruhi capacity pada pemberian pinjaman sebesar $=0,041$. $b_{3}=0,734$ menunjukkan koefisien regresi untuk $X_{3}$. Hal ini berarti jika variabel $X_{3}$ naik satu satuan maka mempengaruhi capital pada pemberian pinjaman sebesar $=-0,734$. $\mathrm{b}_{4}=0,311$ menunjukkan koefisien regresi untuk $\mathrm{X}_{4}$. Hal ini berarti jika variabel $\mathrm{X}_{4}$ naik satu satuan maka mempengaruhi collateral pada pemberian pinjaman sebesar $=0,311$. $b_{5}=0,295$ menunjukkan koefisien regresi untuk $X_{5}$. Hal ini berarti jika variabel $X_{5}$ naik satu satuan maka mempengaruhi condition of economy pada pemberian pinjaman sebesar $=0,295$.

2.4 Hasil uji koefisien determinasi ,didapatkan kesimpulan bahwa pengaruh variabel bebas (character, capacity, capital, collateral, condition of economy) terhadap pemberian pinjaman memberikan kontribusi sebesar 56,5\% sedangkan sisanya 43,5 dijelaskan oleh variabel bebas lain yang tidak diteliti.

2.5 Hasil uji $\mathrm{t}$ di peroleh nilai $\mathrm{t}_{\text {hitung }}$ (X1) 2,355 $>\mathrm{t}_{\text {tabel }}$ 1,99495 sehingga $\mathrm{H}_{0}$ ditolak dan $\mathrm{H}_{1}$ diterima yang berarti bahwa character mempunyai pengaruh yang signifikan secara parsial terhadap pemberian pinjaman. Sedangkan nilai $t_{\text {hitung }}(X 2)=0,225<$ $\mathrm{t}_{\text {tabel }}=1,99495$ sehingga $\mathrm{H}_{0}$ diterima $\mathrm{H}_{1}$ diteolak yang berarti bahwa capacity tidak mempunyai pengaruh yang signifikan secara parsial terhadap pemberian pinjaman. 
Nilai $t_{\text {hitung }}(\mathrm{X} 3)$ 4,380 $>\mathrm{t}_{\text {tabel }} 1,99495$ sehingga $\mathrm{H}_{0}$ ditolak dan $\mathrm{H}_{1}$ diterima yang berarti bahwa capital mempunyai pengaruh yang signifikan secara parsial terhadap pemberian pinjaman. Nilai $t_{\text {hitung }}(\mathrm{X} 4) 1,753<\mathrm{t}_{\text {tabel }} 1,99495$ sehingga $\mathrm{H}_{0}$ diterima dan $\mathrm{H}_{1}$ ditolak yang berarti bahwa collateral tidak mempunyai pengaruh yang signifikan secara parsial terhadap pemberian pinjaman. nilai $t_{\text {hitung }}$ (X5) $1,397<t_{\text {tabel }} 1,99495$ sehingga $\mathrm{H}_{0}$ diterima dan $\mathrm{H}_{1}$ ditolak yang berarti bahwa condition of economy tidak mempunyai pengaruh yang signifikan secara parsial terhadap pemberian pinjaman. Hasil penguji ini sejalan dengan penelitian terdahulu, yaitu yang dilakuka Fanny Azizah (2016) yang berjudul "pengaruh penilaian kelayakan kredit terhadap keputusan pemberian kredit" menyatakan bahwa capacity, collateral dan condition of economi tidak berpengaruh signifikan secara parsial dalam pemerian kredit.

2.6 Hasil uji $F$ pada tabel anova diperoleh nilai $F_{\text {hitung }} 9,170>F_{\text {tabel }} 2,35$ sehingga $\mathrm{H}_{0}$ ditolak dan $\mathrm{H}_{1}$ diterima yang berarti bahwa variabel character $(\mathrm{X} 1)$, capacity $(\mathrm{X} 2)$, capital (X3), collateral (X4) dan condition of economy (X5) mempunyai pengaruh yang signifikan secara simultan terhadap pemberian pinjaman pada KSU Kencana Makmur Sugihan. Hasil penguji ini sejalan dengan penelitian terdahulu, yaitu yang dilakukan Siska Maristiana et.al Agus Supriyanti, S,E. M,M (2017) dengan judul "pengaruh analisi 5C (character, capacity, capital, collateral, condition of economi) dalam pemberian kredit" menyatakan bahwa character, capacity, capital, collateral, condition of economi berpengaruh signifikan terhadap pemberian pinjaman. Hasil penguji ini sejalan juga dengan penelitian terdahulu, yaitu yang dilakukan Dwi Wulandari (2018) yang berjudul "pengaruh five " $C$ " $S$ Of credit terhadap proses pemberian kredit" menyatakan bahwa character, capacity, capital, collateral, condition of economi mempunyai pengaruh yang signifikan terhadap pemberian kredit.

\section{KESIMPULAN}

Berdasarkan hasil analisis dan hasil pembahasan tentang character, capacity, capital, collateral dan condition of economy terhadap pemberian pinjaman pada KSU Kencana Makmur Sugihan maka diperoleh kesimpulan sebagai berikut : Dari hasil uji t di peroleh nilai thitung character (X1) 2,355 > t tabel 1,99495, Sedangkan nilai thitung capacity (X2) $0,255<$ tabel 1,99495. Nilai thitung capital (X3) 4,380 > tabel 1,99495. Nilai thitung collateral (X4) $1,753<\mathrm{t}_{\text {tabel }} 1,99495$. Nilai thitung condition of economy (X5) $1,397<\mathrm{t}_{\text {tabel }}$ 1,99495 .

Dari hasil uji F pada tabel anova diperoleh nilai $F_{\text {hitung }} 9,170>F_{\text {tabel }}$ 2,35 bahwa variabel character (X1), capacity (X2), capital (X3), collateral (X4) dan condition of economy (X5) mempunyai pengaruh yang signifikan secara simultan terhadap pemberian pinjaman pada KSU Kencana Makmur Sugihan.

Dari hasil regresi berganda dapat ditarik persamaan regresinya yaitu, $\mathrm{Y}=0,419+$ $0,604 X_{1}+0,8041 X_{2}-0,735 X_{3}+0,311 X_{4}+0,295 X_{5}$ dimana $\alpha=0,419$ adalah konstanta yang menunjukkan interpretasi dari nilai $Y$ (pemberian pinjaman) pada saat nilai $X$ sama dengan nol. $b_{1}=0,604$ menunjukkan koefisien regresi untuk $X_{1}$ (character). $b_{2}=0,041$ menunjukkan koefisien regresi untuk $\mathrm{X}_{2}$ (capacity). $\mathrm{b}_{3}=0,734$ menunjukkan koefisien regresi untuk $\mathrm{X}_{3}$ (capital). $\mathrm{b}_{4}=0,311$ menunjukkan koefisien regresi untuk $\mathrm{X}_{4}$ (collateral). $\mathrm{b}_{5}=0,295$ menunjukkan koefisien regresi untuk $\mathrm{X}_{5}$ (condition of economy). ). Dari perhitungan tersebut dapat disimpulkan bahwa Capital berpengaruh paling 
dominan terhadap pemberian pinjaman karena nilai koefisien capital $(0,734)$ lebih besar daripada nilai koefisien character $(0,604)$, capacity $(0,041)$, collateral $(0,311)$, condition of economy $(0,295)$.

\section{DAFTAR PUSTAKA}

Anggriawan, I. G. B. F., Herawati, N. T., AK, S., \& Purnamawati, I. G. A. (2017). ANALISIS PRINSIP 5C DAN 7P DALAM PEMBERIAN KREDIT UNTUK MEMINIMALISIR KREDIT BERMASALAH DAN MENINGKATKAN PROFITABILITAS (STUDI KASUS PADA PT. BPR PASAR UMUM DENPASAR-BALI). JIMAT (Jurnal Ilmiah Mahasiswa Akuntansi) Undiksha, 8(2).

AZIZA, F. (2016). PENGARUH PENILAIAN KELAYAKAN KREDIT TERHADAPKEPUTUSAN PEMBERIAN KREDIT PADA BANK PERKREDITAN RAKYAT DI SURABAYA (Doctoral dissertation, STIE PERBANAS SURABAYA).

Dewi, P., Nainggolan, P., Tarigan, P., \& Jubi, J. (2018). ANALISIS PERKEMBANGAN MODAL SENDIRI DAN PEMBERIAN PINJAMAN UNTUK MENINGKATKAN SISA HASIL USAHA PADA KOPERASI KREDIT CU MANDIRI TEBING TINGGI. FINANCIAL, 2(1).

Karamina, A. (2012). Analisis Pengaruh Informasi Akuntansi dan Informasi Non Akuntansi terhadap Keputusan Kredit. Accounting Analysis Journal, 1(2).

Lubis, I. (2010). Bank dan Lembaga Keuangan. USUpress.

Lailiyah, A. (2014). Urgensi Analisa 5c Pada Pemberian Kredit Perbankan Untuk Meminimalisir Resiko. Yuridika, 29(2).

Oktafiani, L., \& Idris, I. (2015). Pelaksanaan Pemberian Kredit dengan Jaminan Hak Tanggungan pada Debitur PT. Bank DKI Jakarta Pusat. Lex Jurnalica, 12(2), 147323

Prayetno, P., \& Muslihudin, M. Model Sistem Pendukung Keputusan Penilaian Kelayakan Pemberian Kredit. None, 1(1), 248-258.

Supramono, G. (2009). Perbankan dan masalah kredit: suatu tinjauan bidang yuridis. Rineka Cipta.Syairozi, M. I., \& Fattah, A. (2018). "Youth Creative Entrepreneur Empowerment (YOUTIVEE)": Solusi Bagi Kaum Muda untuk Berkonstribusi Pada Perekonomian dan Mengurangi Pengganguran. Jesya (Jurnal Ekonomi \& Ekonomi Syariah), 1(2), 43-55. 
Syairozi, M. I., \& Susanti, I. (2018). Analisis Jumlah Pengangguran dan Ketenagakerjaan terhadap Keberadaan Usaha Mikro Kecil dan Menengah di Kabupaten Pasuruan. Jurnal Samudra Ekonomi dan Bisnis, 9(2), 198-208.

Wahyuni, N. (2017). PENERAPAN PRINSIP 5C DALAM PEMBERIAN KREDIT SEBAGAI PERLINDUNGAN BANK. Lex Journal: Kajian Hukum \& Keadilan, 1(1).

Widiastoeti, H., \& Sari, C. A. E. (2020). Penerapan Laporan Keuangan Berbasis SAKEMKM Terhadap Kualitas Laporan Keuanagan pada UMKM Kampung KUE di Rungkut Surabaya. JURNAL EKBIS: ANALISIS, PREDIKSI DAN INFORMASI, 21(1), 1-15.

Wulandari, D. A. D. (2012). Pengaruh Five "C" S Of Credit Terhadap Proses Pemberian Kredit Pada BPR Di Kota Semarang. Jurnal Ilmu Administrasi Bisnis, 1(2), 212225. 